\title{
Synthesis and Crystal Structure of New bis(Azacrown Ethers) on the Basis of 1,2-bis $(2,2,2-$ Trichloro-1-isocyanatoethoxy)benzene
}

\author{
Nickolay G. Luk'yanenko, ${ }^{\circledR, a}$ Viktor N. Pastushok, ${ }^{a}$ Alexandr Yu. Lyapunov, ${ }^{a}$

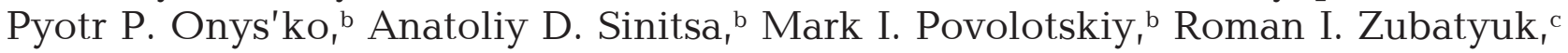 \\ and Oleg V. Shishkin ${ }^{\mathrm{c}}$ \\ ${ }^{a}$ A. V. Bogatsky Physico-Chemical Institute National Academy of Sciences of Ukraine, Odessa, 65080, Ukraine \\ 'Institute of Organic Chemistry National Academy of Sciences of Ukraine, Kiev, 02094, Ukraine \\ "STC “Institute for Single Crystals” National Academy of Sciences of Ukraine, Kharkov, 61001, Ukraine \\ @ Corresponding author E-mail: ngl@farlep.net
}

\begin{abstract}
Synthesis, properties and X-Ray analysis of the new bis(azacrown ethers), containing bridging ureid fragments, are described. These substances have in their molecule structure both centers of anion linking (proton donating NH groups) and centers of cation linking (crown ether units) and thus may be considered as potential ion-pare receptors.
\end{abstract}

Keywords: Azacrown ethers, ion-pair receptor, X-Ray crystal structure.

\section{Синтез и кристаллическая структура новых бис(азакраун-эфиров) на основе 1,2-бис (2,2,2-трихлоро-1-изоцианатоэтокси)бензола}

\author{
Н.Г. Аукьяненко, ${ }^{\circledR, a}$ В.Н. Пастушок, ${ }^{\text {a }}$ А.Ю. Аяпунов, ${ }_{1}^{\text {b }}$ П.П. Онысько, ${ }^{\text {b }}$ \\ А.А. Синица, ${ }^{\text {b }}$ М.И. Поволоцкий, ${ }^{\text {b }}$ Р.И. Зубатюк', О.В. Шишкин ${ }^{c}$ \\ ${ }^{\mathrm{a}}$ Физико-химический институт имени А.В. Богатского Наџиональной академии наук Украины, \\ Одесса, 65080, Украина \\ 'Институт органической химии Национальной академии наук Украины, Киев, 02094, Украина \\ 'НТК “Институт монокристаллов” Национальной академии наук Украинь,, Харьков, 61001, Украина \\ @E-mail:ngl@farlep.net
}

\begin{abstract}
Описан синтез, свойства и рентгеноструктурный анализ новых бис(азакраун-эфиров), содержаших уреидные фрагменты в качестве соединяющего мостика. Одновременное присутствие в молекуле протонодонорных NH фрагментов (места связывания анионов) и краун-эфирных единиц (места связывания катионов) позволяет рассматривать эти вещества как потенциальные ион-парные рецепторы.
\end{abstract}

Ключевые слова: Азакраун-эфиры, ион-парные рецепторы, кристаллическая структура.

\section{Введение}

Анионы играют важную роль во многих химических и биологических процессах. Поэтому конструирование и синтез селективных рецепторов анионов является важной и актуальной задачей. ${ }^{[1]}$ За последнее десятилетие синтезировано много ациклических и циклических гомотопных рецепторов анионов, содержащих, как правило, амидные или уреидные группы. ${ }^{[2-6]}$ Последние являются хорошими Н-донорами, что обеспечивает прочное и достаточно селективное связывание анионов при образовании с ними водородных связей. В последнее время большое внимание привлекают гетеродитоп- ные рецепторы, содержащие различные по природе места связывания аниона и катиона, что делает возможным связывание ими субстрата в виде ионной пары (ионпарное распознавание). Такие соединения способны увеличивать липофильность и растворимость ионных пар в неполярной среде, что дает возможность их эффективного применения в экстракционных системах и в процессах мембранного транспорта. ${ }^{[7-11]}$ Кроме того, ионпарные рецепторы способны к координированию важных биологических молекул, таких как цвиттерионы аминокислот и пептидов. ${ }^{[12,13]}$

В качестве рецепторов ионных пар перспективными представляются бис(краун-эфиры), в которых два краун- 
эфирных цикла (места связывания катионов) соединены относительно жесткой цепочкой, содержащей фрагменты мочевины (места связывания анионов). В настоящем сообщении мы описываем синтез, свойства и кристаллическую структуру новых бис(азакраун-эфиров) на основе 1,2-бис(2,2,2-трихлоро-1-изоцианатоэтокси)бензола. Наличие в цепочке, связывающей азакраун-эфиры, электроотрицательных и липофильных трихлорметильных групп должно увеличивать NH-кислотность уреидных групп, следовательно, и прочность связывания анионов, а также растворимость этих соединений в малополярных средах.

\section{Экспериментальная часть}

Спектры ${ }^{1} \mathrm{H}$ и ${ }^{13} \mathrm{C}$ ЯМР регистрировали в растворах $\mathrm{CDCl}_{3}$ или DMSO- $d_{6}$ на приборах Varian VXR-300 $\left({ }^{1} \mathrm{H}\right)$ и Bruker Avance DRX $500\left({ }^{13} \mathrm{C}\right)$ с рабочими частотами 300 и 125.76 МГц соответственно. ББА-масс-спектры - на масс-спектрометре VG 7070EQ (Хе, 8 кВ) в матрице 3-нитробензилового спирта. Элементный анализ проводили на CHNS анализаторе EuroVector EA3000. Чистоту всех синтезированных веществ контролировали методом тонкослойной хроматографии ТСХ (Sorbfil УФ-254). Температуры плавления измерены в открытых капиллярах и не исправлены. 1,2-Бис(2,2,2-трихлоро-1изоцианатоэтокси)бензол $\mathbf{1}^{[14]}$ и азакраун-эфиры $2^{[15]} \mathbf{3}^{[16]}$ и $\mathbf{4}^{[17]}$ получали как описано ранее. Рентгеноструктурные исследования соединений 5-7 были проведены при температуре $100 \mathrm{~K}$ на автоматическом четырехкружном диффрактометре "Xcalibur 3" (излучение MoK $\alpha$, графитовый монохроматор, $\mathrm{CCD}$ детектор, $\omega$ и $\varphi$-сканирования). Структуры расшифрованы прямыми методами и уточнены полноматричным методом наименьших квадратов МНК в анизотропном приближении для неводородных атомов с помощью пакета программ SHELX-97. ${ }^{[18]}$ Положения атомов водорода рассчитаны геометрически и уточнены по модели наездника с $U_{\text {изо }}=1.2 U_{\text {экв }}$ связанного с ними атома, за исключением амидных атомов водорода в структурах 5 и 7 , которые уточнялись независимо. При уточнении структур 5-7 налагались ограничения на длины связей в разупорядоченных фрагментах макроцикла $(\mathrm{C}-\mathrm{C}$ 1,52(1) $\AA$ и С-O 1,43(1) $\AA$ ), а также на 1,3 расстояния для фиксирования величин валентных углов (C-C 2,36(3) $\AA$ и $\mathrm{C}-\mathrm{O}$ $2,40(3) \AA$ ). Кроме того, при уточнении структуры 6 налагались ограничения на разность компонент тензоров тепловых колебаний вдоль линий связей в разупорядоченных фрагментах с точностью $0,01 \AA^{2}$ (модель жестких связей). Кристаллографические данные приведены в Таблице 1. Структурная информация была депонирована в Кембриджский банк структурных данных. Номера депозитов: 718588 (5), 718589 (6), 718590 (7).

Пригодные для рентгеноструктурного исследования кристаллы соединений 5,6 и 7 получали кристаллизацией их из метанола, смеси 2-пропанола с гексаном (3:1) и этанола, соответственно.

Таблица 1. Кристаллографические данные для структур 5-7.

\begin{tabular}{|c|c|c|c|}
\hline & 5 & 6 & 7 \\
\hline Брутто-формула & $\mathrm{C}_{32} \mathrm{H}_{48} \mathrm{~N}_{4} \mathrm{O}_{12} \mathrm{Cl}_{6}$ & $\mathrm{C}_{36} \mathrm{H}_{56} \mathrm{~N}_{4} \mathrm{O}_{14} \mathrm{Cl}_{6}$ & $\mathrm{C}_{40} \mathrm{H}_{48} \mathrm{~N}_{4} \mathrm{O}_{12} \mathrm{Cl}_{6}$ \\
\hline Температура, K & 100 & 100 & 100 \\
\hline Сингония & Триклинная & Триклинная & Триклинная \\
\hline Пространственная группа & $P-1$ & $P-1$ & $P-1$ \\
\hline$a(\AA)$ & $12.3537(7)$ & $10.3919(3)$ & $9.8658(2)$ \\
\hline$b(\AA)$ & $12.7623(6)$ & $12.8123(5)$ & $13.0262(3)$ \\
\hline$c(\AA)$ & $14.9682(7)$ & $19.4032(6)$ & $18.8532(3)$ \\
\hline$\alpha$ (град) & $78.940(4)$ & $78.120(3)$ & $95.2210(10)$ \\
\hline$\beta$ (град) & $73.909(5)$ & $82.965(3)$ & $98.2320(10)$ \\
\hline$\gamma($ град) & $69.761(5)$ & $69.961(3)$ & $106.873(2)$ \\
\hline$V\left(\AA^{3}\right)$ & $2115.37(18)$ & $2371.24(14)$ & $2272.12(8)$ \\
\hline Z & 2 & 2 & 2 \\
\hline$d_{6 ы \varphi}\left(\Gamma / \mathrm{cm}^{3}\right)$ & 1.403 & 1.375 & 1.446 \\
\hline$\mu\left(\mathrm{MM}^{-1}\right)$ & 0.47 & 0.43 & 0.44 \\
\hline $\mathrm{F}\left(\begin{array}{lll}0 & 0 & 0\end{array}\right)$ & 932 & 1028 & 1028 \\
\hline $2 \theta_{\max }($ град) & 52 & 52 & 60 \\
\hline Число измеренных отражений & 35900 & 20663 & 28479 \\
\hline \multirow{2}{*}{ Число независимых отражений } & 8305 & 9082 & 12832 \\
\hline & $R_{\text {int }}=0.036$ & $R_{\text {int }}=0.039$ & $R_{\text {int }}=0.013$ \\
\hline $\begin{array}{l}\text { Количество уточняемых } \\
\text { (количество ограничений) }\end{array}$ & $505(4)$ & $624(68)$ & $586(12)$ \\
\hline$R_{l}[I>2 \sigma(I)]$ & $0.080[4645]$ & $0.052[3024]$ & $0.042[8704]$ \\
\hline$w R_{2}$ (по всем отражениям) & 0.085 & 0.101 & 0.136 \\
\hline Добротность подгонки & 0.95 & 0.94 & 1.03 \\
\hline $\begin{array}{l}\text { Остаточная разностная электронная } \\
\text { плотность, мин/макс }\end{array}$ & $0.446 /-0.345$ & $0.498 /-0.245$ & $0.668 /-0.446$ \\
\hline
\end{tabular}




\section{Синтез}

Общая методика получения соединений 5-7. К раствору азакраун-эфира 2-4 (4,66 ммоль) в безводном хлороформе (25 мл) при $24{ }^{\circ} \mathrm{C}$ прибавляли диизоцианат 1 (2,3 ммоль) в виде раствора в безводном хлороформе $(9,5$ мл, $\mathrm{C}=0,242$ моль/л) в течение 10 мин. Смесь перемешивали при той же температуре 8 ч, прибавляли 15 мл разбавленной $\mathrm{HCl}$ до $\mathrm{p} H \approx 5$ и перемешивали еще 30 мин. Органический слой отделяли, промывали водой до нейтральной реакции $(2 \times 20$ мл) и сушили безводным сульфатом натрия. Хлороформ отгоняли на ротационном испарителе, остаток перекристаллизовывали.

$N, N^{\prime}-\{1,2-$ Фениленбис[окси-(2,2,2-трихлорметан-1,1диил)]\}-бис(1,4,7,10-тетраокса-13-азаииклопентадекан-13карбоксамид) (5). Выход 1,5 г (73\%), т. пл. $147-148^{\circ} \mathrm{C}$ из МеОН. Найдено, \%: С 43,12, Н 5,49, N 6,30. $\mathrm{C}_{32} \mathrm{H}_{48} \mathrm{Cl}_{6} \mathrm{~N}_{4} \mathrm{O}_{12}$. Вычислено,

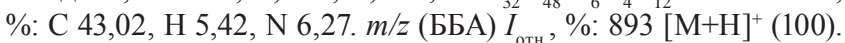
${ }^{1} \mathrm{H}$ ЯМР $\left(\mathrm{CDCl}_{3}\right) \delta_{\mathrm{H}}$ м.д.: 7,67 (2H, д, $\left.J=9,34, \mathrm{NH}\right), 7,32-7,23(2 \mathrm{H}$, м, 4,5- $\left.\mathrm{C}_{6} \mathrm{H}_{4}\right), 7,03-6,95\left(2 \mathrm{H}, \mathrm{м}, 3,6-\mathrm{C}_{6} \mathrm{H}_{4}\right), 6,52(2 \mathrm{H}$, д, $J=9,34$, $\mathrm{CHCCl}_{3}$ ), 3,88-3,24 (40H, м, $\left.\mathrm{CH}_{2} \mathrm{O}, \mathrm{CH}_{2} \mathrm{~N}\right) \cdot{ }^{13} \mathrm{C}$ ЯMP (DMSO- $d_{6}$ )

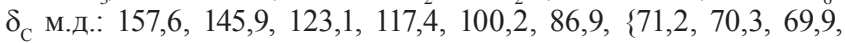
$51,2$ (широкие сигналы) $\}$.

$N, N^{\prime}-\{1,2-$ Фениленбис[окси-(2,2,2-трихлорметан-1,1диил)]\}-бис (1,4,7,10,13-пентаокса-16-азаииклооктадекан-16карбоксамид) (6). Выход 1,6 г (71\%), т. пл. $127-129{ }^{\circ} \mathrm{C}$ из Et $2 \mathrm{O} /$ $\mathrm{C}_{6} \mathrm{H}_{14}$ (3:1). Найдено, \%: C 44,14, Н 5,69, N 5,74. $\mathrm{C}_{36} \mathrm{H}_{56} \mathrm{Cl}_{6} \mathrm{~N}_{4} \mathrm{O}_{14}$. Вычислено, \%: С 44,05, Н 5,75, N 5,71. $\mathrm{m} / z$ (ББА) $I_{\text {оти }}, \%$ : 981 [M $+\mathrm{H}]^{+}(100) .{ }^{1} \mathrm{H}$ ЯМР $\left(\mathrm{CDCl}_{3}\right) \delta_{\mathrm{H}}$ м.д.: 7,55 (2H, д, $\left.J=9,34, \mathrm{NH}\right)$, 7,27-7,20 (2H, м, 4,5- $\left.\mathrm{C}_{6} \mathrm{H}_{4}\right), 7,02-6,94\left(2 \mathrm{H}\right.$, м, 3,6- $\left.\mathrm{C}_{6} \mathrm{H}_{4}\right), 6,55$ $\left(2 \mathrm{H}\right.$, д, $\left.J=9,34, \mathrm{CHCCl}_{3}\right), 3,68-3,39\left(48 \mathrm{H}, \mathrm{м}, \mathrm{CH}_{2} \mathrm{O}, \mathrm{CH}_{2} \mathrm{~N}\right) \cdot{ }^{13} \mathrm{C}$ ЯMP (DMSO- $\left.d_{6}\right) \delta_{\text {С м.д.: } 157,5,144,8,123,2,117,5,114,3-112,9}$ (широкие сигналы), 100,1, 86,9, \{71,6, 71,2, 70,9, 70,6, 70,5 и 49,7 (широкие сигналы) .
$N, N^{\prime}-\{1,2-$ Фениленбис[окси-(2,2,2-трихлорметан-1,1диил)]\}-бис (2,3,5,6,8,9,11,12-октагидро-7Н-1,4,10,13,7-бензотетраоксазаииклопентадеиин-7-карбоксамид) (7). Выход 1,9 г (84\%), т. пл. $188-190{ }^{\circ} \mathrm{C}$ из $\mathrm{EtOH} / \mathrm{CHCl}_{3}$ (50:1). Найдено, \%: $\mathrm{C} 48,05, \mathrm{H} 4,57, \mathrm{~N} 5,70 . \mathrm{C}_{40} \mathrm{H}_{48} \mathrm{Cl}_{6} \mathrm{~N}_{4} \mathrm{O}_{12}$. Вычислено, \%: C 48,55, $\mathrm{H} \mathrm{4,89,} \mathrm{N} \mathrm{5,66.} \mathrm{m} / z$ (ББА) $I_{\text {отн }}, \%: 989[\mathrm{M}+\mathrm{H}]^{+}(100) .{ }^{1} \mathrm{H}$ ЯМР $\left(\mathrm{CDCl}_{3}\right) \delta_{\text {н }}$ м.д.: 7,56 (2H, д, $\left.J=9,65, \mathrm{NH}\right), 7,17-7,09(2 \mathrm{H}, \mathrm{м}, 4,5-$ $\left.\mathrm{C}_{6} \mathrm{H}_{4}\right), 6,93-6,76\left(10 \mathrm{H}\right.$, м, $\left.\mathrm{C}_{6} \mathrm{H}_{4}, 3,6-\mathrm{C}_{6} \mathrm{H}_{4}\right), 6,55(2 \mathrm{H}$, д, $J=9,65$, $\left.\mathrm{CHCCl}_{3}\right), 4,23-3,34\left(32 \mathrm{H}, \mathrm{м}, \mathrm{CH}_{2} \mathrm{O}, \mathrm{CH}_{2} \mathrm{~N}\right) \cdot{ }^{13} \mathrm{C}$ ЯMP (DMSO- $d_{6}$ ) $\delta_{\text {С м.д.: } 157,3,148,5,145,7,123,4,121,4,118,0,114,4-113,0}$ широкий сигнал, 100,1, 86,9, 72,9, 70,4, 69,3, 67,3, 50,8.

\section{Результаты и обсуждение}

Синтез соединений 5-7 осуществляли взаимодействием 1,2-бис(2,2,2-трихлоро-1-изоцианатоэтокси)бензола 1 с двумя эквивалентами соответствующего азакраун-эфира 2-4 в сухом хлороформе при комнатной температуре (Схема 1). Целевые продукты 5-7 были выделены с хорошими выходами (71-84\%) после обработки реакционной массы водной $\mathrm{HCl}$ и перекристаллизации из подходящего растворителя. Все они представляют собой бесцветные кристаллические вещества хорошо растворимые в хлористом метилене, хлороформе, ацетонитриле и ограниченно растворимые в метаноле и этаноле. В спектрах ${ }^{1} \mathrm{H}$ ЯМР бис(азакраунэфиров) 5-7 в $\mathrm{CDCl}_{3}$ присутствуют мультиплетные сигналы метиленовых групп краун-эфиров в области 3,24-4,23 м.д. и сигналы протонов всех функциональных групп связки с соответствующими интенсивностями. Уширение некоторых сигналов в спектрах ${ }^{13} \mathrm{C}$ ЯМР

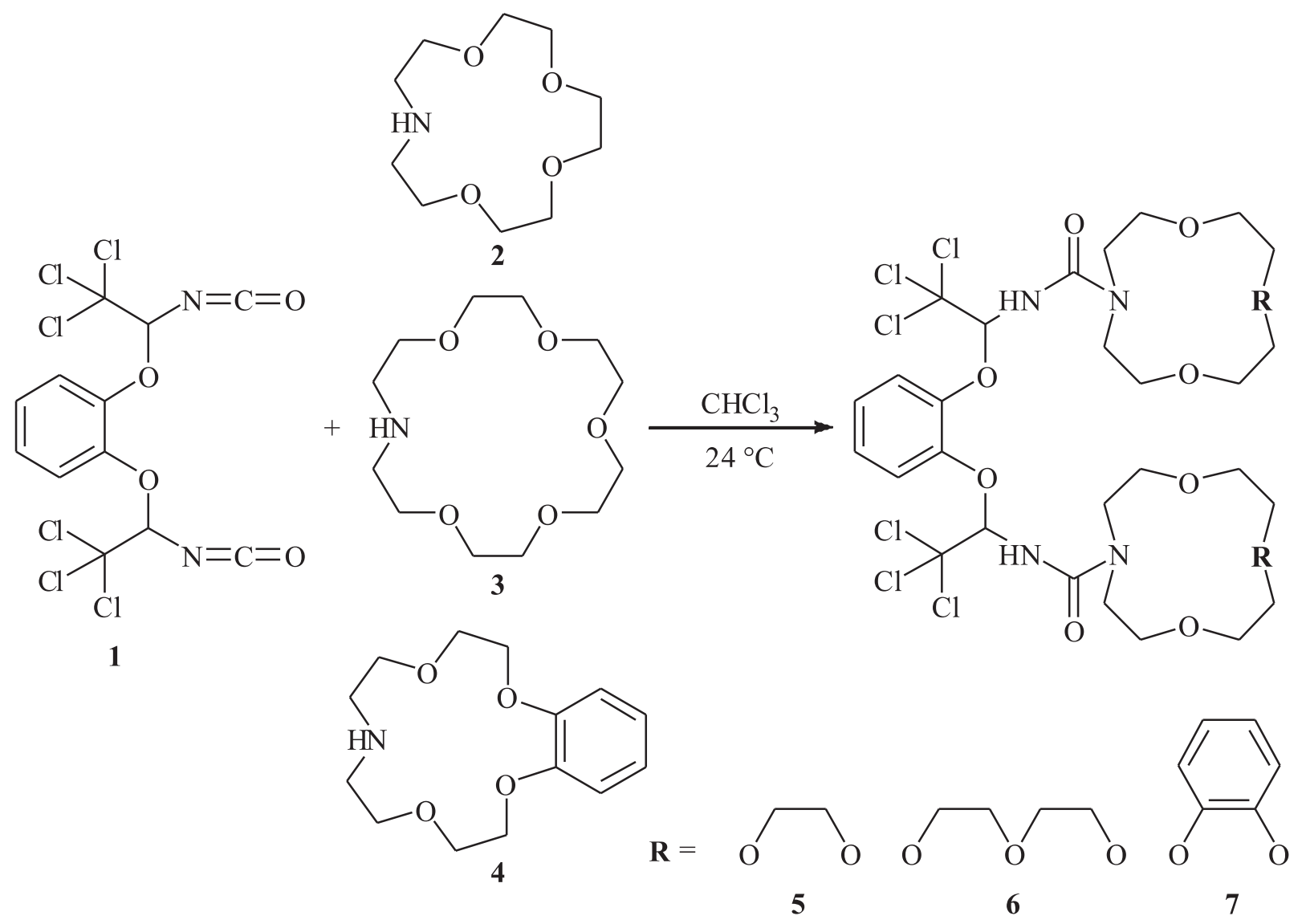

Схема 1. Синтез бис(азакраун-эфиров) 5-7 
соединений 5-7 (см. Экспериментальную часть) свидетельствует о заторможенном вращении вокруг связи

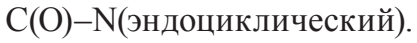

Рентгеноструктурное исследование соединений 5-7 (Рисунки 1-3) показало, что в кристаллах реализуются

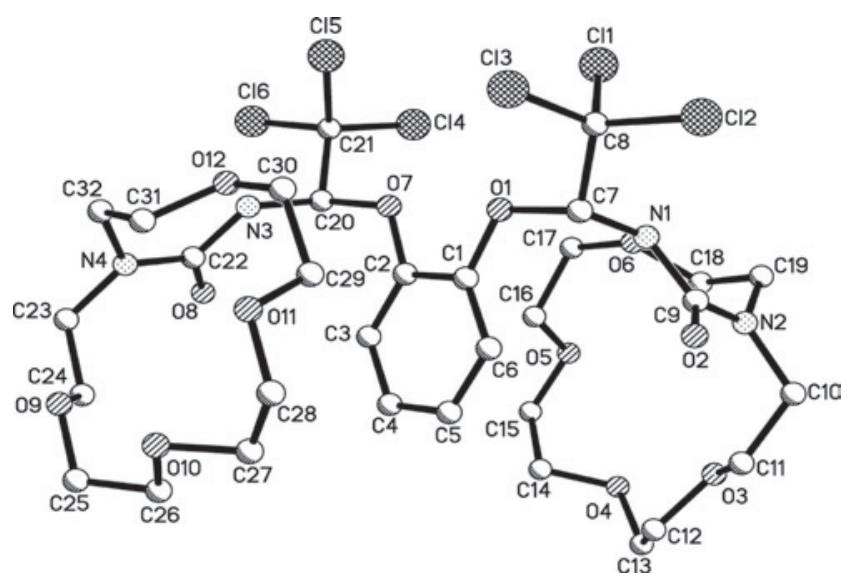

Рисунок 1. Кристаллическая структура соединения 5.

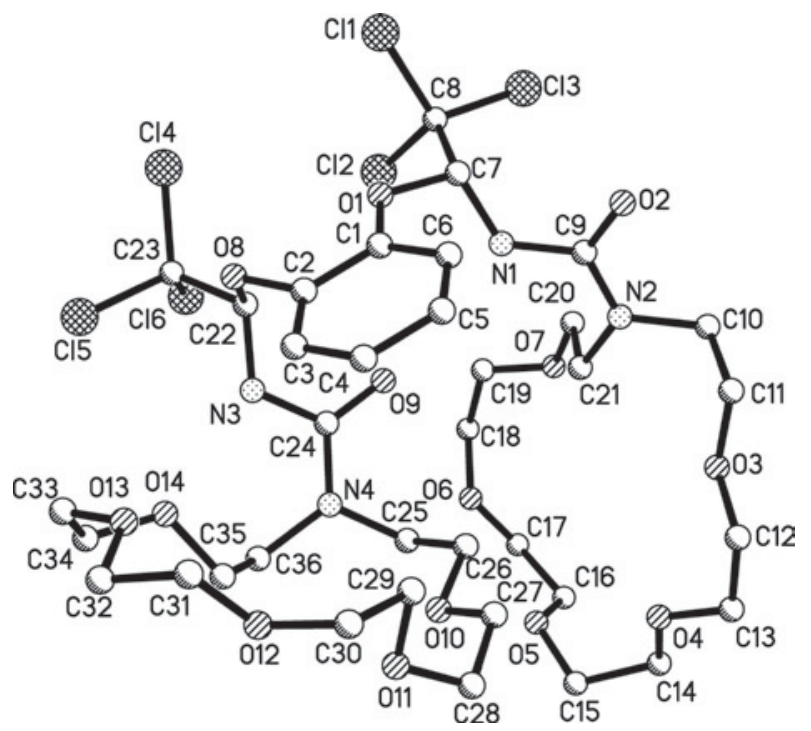

Рисунок 2. Кристаллическая структура соединения 6.

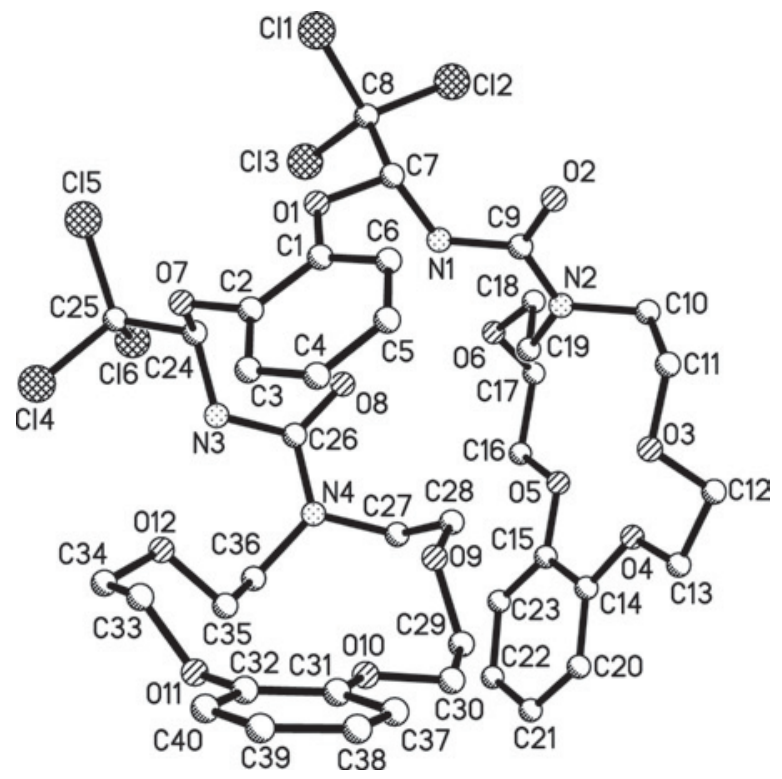

Рисунок 3. Кристаллическая структура соединения 7. два различных типа конформаций молекул, отличающихся, прежде всего, взаимной ориентацией центрального ароматического кольца и краун-эфирных фрагментов.

В соединении 5 связи $\mathrm{O}-\mathrm{CH}\left(\mathrm{CCl}_{3}\right)$ расположены близко к плоскости центрального ароматического цикла (торсионные углы С7-O1-C1-C6 16,3(3) ${ }^{\circ}$ и C20O7-C2-C3 13,7(2) ${ }^{\circ}$. Фрагменты O-CH( $\left.\mathrm{CCl}_{3}\right)-\mathrm{NH}$ имеют $+s c$,-ac конформацию (торсионные углы C1-O1-C7-N1 68,4(2), C2-O7-C20-N3 69,6(2), O1-C7-N1-C9-122,1(2) , O7-C20-N3-C22 -123,5(2) ${ }^{\circ}$. Мочевинные фрагменты практически плоские (торсионные углы C7-N1-C9-N2 $171,36(17)^{\circ}$ и $\left.\mathrm{C} 20-\mathrm{N} 3-\mathrm{C} 22-\mathrm{N} 4172,73(17)^{\circ}\right)$, а средние плоскости азакраун-эфиров развернуты практически перпендикулярно этим фрагментам (углы между средними плоскостями макроциклов и связанных с ними фрагментов $\mathrm{C}-\mathrm{NH}-\mathrm{C}(=\mathrm{O})-\mathrm{N}$ составляют 77$\left.78^{\circ}\right)$. В результате в молекуле 5 бензольное кольцо располагается между двумя макроциклами. При этом средние плоскости бензольного и азакраун-эфирных циклов практически параллельны (углы между ними не превышают $10^{\circ}$ ), расстояния между их центрами составляют 4,3-4,4 $\AA$.

Молекулы 6 и 7 имеют сходный тип конформации. Однако, в отличие от структуры 5, в этих молекулах одна из связей $\mathrm{O}-\mathrm{CH}\left(\mathrm{CCl}_{3}\right)$ немного отклоняется от плоскости центрального ароматического цикла, а другая ориентирована практически перпендикулярно этой плоскости (торсионные углы C7-O1-C1-C6 22,5(5) ${ }^{\circ}$ и С22-O8-C2-C3 -116,3(4) ${ }^{\circ}$ в молекуле 6 и С 7-O1-C1-С6 $24,6(2)^{\circ}$ и С24-О7-С2-С3 -109,17(16) ${ }^{\circ}$ в молекуле 7). При этом конформация фрагментов $\mathrm{O}-\mathrm{CH}\left(\mathrm{CCl}_{3}\right)-\mathrm{NH}$ (торсионные углы C1-O1-C7-N1 61,1(4), C9-N1-C7-O1 $-133,2(3)^{\circ}, \quad \mathrm{C} 2-\mathrm{O} 8-\mathrm{C} 22-\mathrm{N} 3 \quad 65,6(4)^{\circ}, \mathrm{C} 24-\mathrm{N} 3-\mathrm{C} 22-\mathrm{O} 8$ $-108,6(3)^{\circ}$ (6) и С1-O1-C7-N1 63,52(15) ${ }^{\circ}$, C9-N1-C7-O1 $-130,04(13)^{\circ}, \quad \mathrm{C} 2-\mathrm{O} 7-\mathrm{C} 24-\mathrm{N} 3 \quad 58.80(16)^{\circ}, \quad \mathrm{C} 26-\mathrm{N} 3-$ C24-O7 -105,43(15) $\left.{ }^{\circ}(7)\right)$ и мочевинных фрагментов (торсионные углы C7-N1-C9-N2 -175,7(3) ${ }^{\circ}, \mathrm{C} 22-\mathrm{N} 3-$ C24-N4 172,6(3) ${ }^{\circ}$ (6) и C7-N1-C9-N2 -176,94(12), C24N3-C26-N4 172,61(12) ${ }^{\circ}$ (7)) остается практически такой же, как и в молекуле 5. Однако изменение ориентации заместителей при центральном ароматическом кольце приводит к тому, что средняя плоскость макроцикла содержащего атом N4 ориентирована практически перпендикулярно относительно связанного с ним мочевинного фрагмента (углы между средними плоскостями составляют $78^{\circ}(6)$ и $\left.61^{\circ}(7)\right)$, а макроцикл содержащий атом N2 развернут гораздо меньше относительно связанного с ним фрагмента (углы между средними плоскостями составляют $46^{\circ}$ (6) и $49^{\circ}$ (7)). В результате реализуется практически ортогональная взаимная ориентация двух макроциклов (углы между средними плоскостями составляют $79^{\circ}$ (6) и $\left.81^{\circ}(7)\right)$.

Оба типа конформаций, которые наблюдаются в структурах 5-7, стабилизированы за счет образования двух внутримолекулярных водородных связей (Таблица 2). В структуре 5 образуются водородные связи между двумя NH группами мостика и эфирными атомами кислорода азакраун-эфирных циклов. В структурах 6 и 7 образована лишь одна такая связь с участием атома N1. Вторая внутримолекулярная водородная связь образована между двумя уреидными группами (Таблица 2). 
Таблица 2. Геометрические параметры внутримолекулярных водородных связей в структурах 5-7.

\begin{tabular}{clrlc}
\hline \multirow{2}{*}{ Структура } & \multicolumn{1}{c}{ Связь } & $\begin{array}{c}\mathrm{H} \cdots \mathrm{A}, \\
\AA\end{array}$ & $\begin{array}{c}\mathrm{D}-\mathrm{H} \cdots \mathrm{A}, \\
\text { град. }\end{array}$ & $\begin{array}{c}\mathrm{D} \cdots \mathrm{A}, \\
\AA\end{array}$ \\
\hline \multirow{2}{*}{$\mathbf{5}$} & $\mathrm{N} 1-\mathrm{H} 1 \mathrm{~N} \cdots \mathrm{O} 6$ & 2,01 & 160 & 2,762 \\
& $\mathrm{~N} 3-\mathrm{H} 3 \mathrm{~N} \cdots \mathrm{O} 12$ & 2,03 & 159 & 2,760 \\
\hline \multirow{2}{*}{$\mathbf{6}$} & $\mathrm{N} 1-\mathrm{H} 1 \mathrm{~A} \cdots \mathrm{O} 9$ & 2,30 & 148 & 3,069 \\
& $\mathrm{~N} 3-\mathrm{H} 3 \mathrm{~B} \cdots \mathrm{O} 14$ & 2,08 & 139 & 2,788 \\
\hline \multirow{2}{*}{7} & $\mathrm{~N} 1-\mathrm{H} 1 \mathrm{~N} \cdots \mathrm{O} 8$ & 2,21 & 167 & 2,966 \\
& $\mathrm{~N} 3-\mathrm{H} 2 \mathrm{~N} \cdots \mathrm{O} 12$ & 2,06 & 159 & 2,882 \\
\hline
\end{tabular}

\section{Выводы}

В заключение отметим, что нами получены новые бис(краун-эфиры), содержащие уреидные фрагменты в соединительном мостике, и изучено их строение в кристаллическом состоянии. Присутствие в молекуле протонодонорных NH фрагментов и краун-эфирных циклов позволяет рассматривать эти вещества как потенциальные гетеродитопные рецепторы для ионных пар.

\section{Список литературы}

\section{References}

1. Sessler J.L., Gale P.A., Cho W.S. Anion Receptor Chemistry Cambridge: Royal Society of Chemistry, 2006, 414 p.
2. Gale P. A. Coord. Chem. Rev. 2003, 240, 1.

3. Choi K., Hamilton A.D. Coord. Chem. Rev. 2003, 240, 101-110.

4. Bowman-James K. Acc. Chem. Res. 2005, 38, 671-678.

5. Beer P.D., Gale P.A. Angew. Chem. Int. Ed. 2001, 40, 486516.

6. Gale P.A. Acc. Chem. Res. 2006, 39, 465-475.

7. Shukla R., Kida T., Smith B.D. Org. Lett. 2000, 2, 30993102.

8. Koulov A.V., Mahoney J.M., Smith B.D. Org. Biomol. Chem. 2003, 1, 27-29.

9. Mahoney J.M., Davis J.P., Beatty A.M., Smith B.D. J. Org. Chem. 2003, 68, 9819-9820.

10. Mahoney J.M., Stucker K.A., Jiang H., Carmichael I., Brinkmann N.R., Beatty A.M., Noll B.C., Smith B.D. J. Am. Chem. Soc. 2005, 127, 2922-2928.

11. Evans A.J., Beer P.D. Dalton Trans. 2003, 4451-4456.

12. Hossain M.A., Schneider H.-J. J. Am. Chem. Soc. 1998, 120 , 11208-11209.

13. Breccia P., Gool M.V, Pérez-Fernández R., Martín-Santamaría S., Gago F., Prados P., Mendoza J. J. Am. Chem. Soc. 2003, $125,8270-8284$.

14. Kudrya T.N., Talanova G.G., Sinitsa A.D., Bonadyk S.V. Zh. Org. Khim. 1979, 15, 657-658. (in Russ.).

15. Lukyanenko N.G., Kirichenko T.I., Limich V.V., Bogatsky A.V. Khim. Geterotsikl. Soedin. 1987, 263-266. (in Russ.).

16. Maeda H., Nakatsuji Y., Okahara M. J. Chem. Soc., Chem. Commun. 1981, 471-472.

17. Nakamura M., Yokono H., Tomita K., Ouchi M., Miki M., Dohno R. J. Org. Chem. 2002, 67, 3533-3536.

18. Sheldrick G.M. SHELX97 - Programs for Crystal Structure Analysis (Release 97-2), Institüt für Anorganische Chemie der Universität, Tammanstrasse 4, D-3400 Göttingen, Germany, 1998.

Received 18.12.2008

Accepted 11.01.2009

First publish on the web 07.03.2009 